\title{
Mechanisms behind the Temporary Shutdown of Deep Convection in the Labrador Sea: Lessons from the Great Salinity Anomaly Years 1968-71
}

\author{
RENSKE GELDERLOOS* \\ Royal Netherlands Meteorological Institute, De Bilt, Netherlands \\ FIAMMETTA STRANEO \\ Woods Hole Oceanographic Institution, Woods Hole, Massachusetts \\ CAROLINE A. KATSMAN \\ Royal Netherlands Meteorological Institute, De Bilt, Netherlands
}

(Manuscript received 27 September 2011, in final form 19 March 2012)

\begin{abstract}
From 1969 to 1971 convection in the Labrador Sea shut down, thus interrupting the formation of the intermediate/dense water masses. The shutdown has been attributed to the surface freshening induced by the Great Salinity Anomaly (GSA), a freshwater anomaly in the subpolar North Atlantic. The abrupt resumption of convection in 1972, in contrast, is attributed to the extreme atmospheric forcing of that winter. Here oceanic and atmospheric data collected in the Labrador Sea at Ocean Weather Station Bravo and a one-dimensional mixed layer model are used to examine the causes of the shutdown and resumption of convection in detail. These results highlight the tight coupling of the ocean and atmosphere in convection regions and the need to resolve both components to correctly represent convective processes in the ocean. They are also relevant to present-day conditions given the increased ice melt in the Arctic Ocean and from the Greenland Ice Sheet. The analysis herein shows that the shutdown was initiated by the GSA-induced freshening as well as the mild 1968/69 winter. After the shutdown had begun, however, the continuing lateral freshwater flux as well as two positive feedbacks [both associated with the sea surface temperature (SST) decrease due to lack of convective mixing with warmer subsurface water] further inhibited convection. First, the SST decrease reduced the heat flux to the atmosphere by reducing the air-sea temperature gradient. Second, it further reduced the surface buoyancy loss by reducing the thermal expansion coefficient of the surface water. In 1972 convection resumed because of both the extreme atmospheric forcing and advection of saltier waters into the convection region.
\end{abstract}

\section{Introduction}

In the northern North Atlantic the winter heat loss from the ocean to the atmosphere is so extreme that in certain areas, notably the Labrador Sea and the Nordic Seas, the water column becomes statically unstable and convectively mixes surface water downward to form dense water masses (Marshall and Schott 1999). These

* Current affiliation: Department of Earth Sciences, University of Oxford, Oxford, United Kingdom.

Corresponding author address: Renske Gelderloos, Department of Earth Sciences, University of Oxford, South Parks Road, Oxford OX1 3AN, UK.

E-mail: renske.gelderloos@earth.ox.ac.uk convectively formed dense water masses feed the lower limb of the Atlantic meridional overturning circulation (AMOC). Contrary to the classical view (e.g., Stommel 1961), the current understanding is that dense water formation does not act as a driving force for the AMOC (Marotzke and Scott 1999; Kuhlbrodt et al. 2007), but that it is essential for setting its shape and strength and the variability therein (Kuhlbrodt et al. 2007).

The AMOC is responsible for a northward heat transport on the order of $1 \mathrm{PW}\left(1 \mathrm{PW}=10^{15} \mathrm{~W}\right.$; Ganachaud and Wunsch 2000) and therefore plays an important role in the climate system. Major abrupt climate changes in the past have been attributed to large changes in the AMOC (Broecker et al. 1985; Broecker 1997; Clark et al. 2002; Alley et al. 2003), and a shutdown of the AMOC would have significant consequences for the 
oceanic heat supply to the North Atlantic region. As argued by Kuhlbrodt et al. (2007), the strength of the AMOC is set by dense water formation processes, and models show a strong correlation between the variability in deep Labrador Sea convection and AMOC variations on interannual to decadal time scales (Eden and Willebrand 2001; Biastoch et al. 2008). Both in modern times and in past and future climate scenarios, a slowdown or collapse of the AMOC is typically associated with a reduction of convection in the North Atlantic. To accurately simulate AMOC variability and its consequences for climate, it is thus very important to understand what causes deep convective variability in the Labrador Sea. In this paper we study the details of the extreme case of a complete convective shutdown.

Two mechanisms are often proposed in literature as a potential cause of a shutdown of deep convective activity in the Labrador Sea: 1) a reduction in the heat (buoyancy) loss to the atmosphere, which drives deep convection, and 2) a convergence of buoyant (typically fresh) water in the convection region due to advection by the ocean circulation. Variations in the heat loss have generally followed the phase of the North Atlantic Oscillation (NAO) for at least the length of the instrumental records (Curry et al. 1998; Yashayaev 2007). In the early 1990s, for example, the deepest convection on record (up to $2400 \mathrm{~m}$ ) was observed in the Labrador Sea when the NAO index was high for several years. The convergence of buoyant water, on the other hand, is associated with a lateral influx from the boundary currents surrounding the Labrador Sea (Straneo 2006a). Variations in the boundary current characteristics, due to changes either in the freshwater carried at the surface or in the warm, salty Irminger water found below it, can thus also influence convective activity (Lazier 1980; Dickson et al. 1988; Curry et al. 1998; Häkkinen 1999; Houghton and Visbeck 2002; Mizoguchi et al. 2003; Straneo 2006a). Many studies of the distant past, recent history, and future scenarios point to large freshwater anomalies as means of shutting down convection and affecting the AMOC, but the details on how this happens are unclear.

A well-known example of the second mechanism in recent history, which could shed more light on how freshwater anomalies cause deep convection to shut down, occurred when the Great Salinity Anomaly (GSA; Dickson et al. 1988), a low salinity signal, passed through the Labrador Sea in the late 1960s and early 1970s and restricted convection to the upper $\sim 300 \mathrm{~m}$ (Lazier 1980). This event, however, also coincided with a low NAO period, raising the question of how mild winters may have contributed to the shutdown. In the early 1980 s convection was also strongly reduced by a freshwater anomaly (Belkin et al. 1998), yet this occurred during a high NAO period (Curry et al. 1998). Several model studies have been carried out with the aim of determining the dominant factor of the two in shutting down convective activity in the Labrador Sea during the GSA, but the results are conflicting (Häkkinen 1999; Haak et al. 2003; Mizoguchi et al. 2003).

The GSA is a particularly interesting case in recent history as deep convection was completely shut down for three winters in a row. In 1968 the GSA entered the Labrador Sea and caused a substantial freshening of the surface layer, increasing the ocean stratification. During the three following winters, all particularly mild, the convection depth did not exceed the extent of the fresh surface layer. It was not until the winter of 1971/72 (hereafter we will refer to this winter as 1972), one of the harshest winters on record in this region (Uppala et al. 2005, see also Fig. 8), that deep convection resumed to 1500-m depth. The traditional view (e.g., Dickson et al. 1988 ) is that the large fresh surface anomaly of the GSA increased the ocean stratification and thereby inhibited convective mixing, after which the very harsh winter of 1972 made convection resume. Curry et al. (1998) noted that the mild winters could have played a role as well in shutting down convection, but stated that the phase of the NAO was of minor importance based on the notion that the low-salinity event that restricted the convection depth in the 1980s coincided with a high NAO period. Yet, to date, the exact mechanism by which convection shut down has not been identified.

Here we examine in depth the relative contribution of the mild winters and of the surface freshening in shutting down convection from 1968 to 1971. Furthermore, we analyze an important feedback of the presence of the GSA on the surface buoyancy flux. Under typical deep convection conditions, warm subsurface water is mixed upward, keeping the surface water relatively warm and enhancing the air-sea temperature gradient and, thus, the surface heat loss. On the other hand, if no deep convection occurs the surface becomes anomalously cold. Colder water is denser, which could in theory facilitate convection, but because of the larger impact of a low salinity on the water density this does not occur. The low temperature of the water also decreases the surface heat flux, which depends on the temperature gradient between the relatively warm ocean and the cold atmosphere. Moreover, it limits the surface buoyancy flux by affecting the thermal expansion coefficient, which is smaller for lower temperatures. These observations suggest that once convection has stopped, its resumption becomes increasingly more difficult. This is not only because of the increasing stratification of the ocean (as been noted before; Dickson et al. 1988), but 
also because the surface ocean properties actively decrease the magnitude of the surface buoyancy flux. Thus, in order to understand the full impact of freshening on deep convection-an important current topic with the increasing ice melt rates in the Arctic region (Maslanik et al. 2011; Kwok et al. 2009; Rignot et al. 2011) - a more quantitative understanding of these feedbacks is required.

To address these questions we use the oceanographic dataset from Ocean Weather Station Bravo (hereafter OWS Bravo), which comprises frequent oceanographic measurements taken from 1964 to 1974 along with the usual atmospheric observations (Lazier 1980). This dataset has, fortuitously, carefully documented the only complete shutdown of deep convection in the Labrador Sea in the past decades. We also investigate the causes of the return of deep convection in the winter of 1972. By unraveling the details of this particular event we hope to shed light on the mechanisms leading to both a shutdown and a return of deep convection, which will help to understand past and future climate scenarios involving convective shutdowns.

The paper is structured as follows. In sections 2 and 3 the observational data used in this study are presented (the hydrographic observations in section 2 and the airsea fluxes in section 3 ). These data are carefully analyzed in section 4 to assess the relative importance of the mild winters versus the low surface salinity in the shutdown of deep convection in the winters of 1969 to 1971. First, in section $4 \mathrm{a}$ we discuss the increasing stratification that is traditionally assumed to be responsible for the absence of deep convection in these years. Then, using bulk formulas, in section $4 \mathrm{~b}$ the impact of the low sea surface temperature (SST) on the surface buoyancy fluxes is analyzed, which could have played a role in the persistence of the nonconvective state (through the surface feedbacks). Also, the effect of the mild winters on the surface buoyancy flux is quantified in this section. Finally, the actual impacts of the ocean surface feedbacks and the mild winters on the convection depth are quantified using a simple 1D mixed layer model in section 4c. In section 5 the same model is used to investigate the return of deep convection in 1972. The results presented in this study are summarized and discussed in section 6 .

\section{Hydrographic characteristics at OWS Bravo}

The oceanic part of the OWS Bravo dataset (Fig. 1) comprises 11 years of year-round, relatively high-frequency oceanographic measurements, from January 1964 to September 1974 (Lazier 1980). The sampling rate during this period varied between $6 \mathrm{~h}$ and 2 months. Here we use monthly averages of the data interpolated to standard depth levels (Kuhlbrodt et al. 2001). Linear interpolation was used for months when data were missing.

The upper $1500 \mathrm{~m}$ in the interior Labrador Sea broadly consist of three layers (Straneo 2006a,b; Yashayaev 2007). The upper layer, which typically occupies the upper $\sim 200 \mathrm{~m}$, is fed by the fresh and cold boundary current water of Arctic origin found on the continental shelves. The lower boundary of this layer is indicated in Fig. 1 by the thick gray line, which represents the $S=34.75$ psu isohaline. ${ }^{1}$ Below that layer resides a relatively warm and saline layer, which is typically found between $\sim 200$ - and 800-m depth. It obtains its properties from the Irminger Current that carries water of subtropical origin, and encircles the basin while it follows the continental slope. In Fig. 1 this layer is found between the thick gray line and the thick black line. The latter represents the $\sigma_{\theta}=27.72 \mathrm{~kg} \mathrm{~m}^{-3}$ isopycnal, which marks the upper boundary of the Labrador Sea Water (LSW) layer (Straneo 2006a). Note that the results we will present are not very sensitive to the exact values of the dividing isohaline and isopycnal.

The first five years and the last three years of the time series in Fig. 1 show a clear seasonal cycle. In winter the water is convectively mixed to one homogeneous layer ${ }^{2}$ of several hundred meters or more. During spring and summer, the water column is restratified and the three layers reappear. In the winters of 1969, 1970, and 1971, however, no deep convective mixing was observed (Fig. 1d). This period coincided with the time when the GSA passed through the Labrador Sea, as seen by the large freshening of the surface layer (Fig. 1a). During this period a thickening of the upper two layers is observed, with cold and freshwater accumulating in the surface layer and the subsurface waters becoming increasingly warmer and saltier (Figs. 1a,b). The result was a rapid increase in the stratification during these years (Fig. 1c).

\footnotetext{
${ }^{1}$ The oceanographic community is currently moving toward the use of a new equation of state, TEOS10 (IOC et al. 2010), in which the practical salinity is replaced by absolute salinity. For easier reference to earlier literature on OWS Bravo data and as the difference between practical and absolute salinity is negligible in the Labrador Sea (McDougall et al. 2009), we used psu throughout this paper.

${ }^{2}$ As in Lazier (1980), the mixed layer depths in Fig. 1d are based on a subjective estimate of the depth to which cold and fresh surface water was mixed downward (i.e., to the depth to which convective mixing appeared to have influenced the temperature and salinity). The values are all within $100 \mathrm{~m}$ of Lazier's MLD estimates (Lazier 1980), except for 1973, for which Lazier's estimate is $600 \mathrm{~m}$ shallower, and 1974, for which no winter estimate was given. The reason for Lazier's low estimate for 1973 is unclear, as his Fig. 4 clearly shows similar cooling at 1500-m depth in the winters of 1972 and 1973.
} 


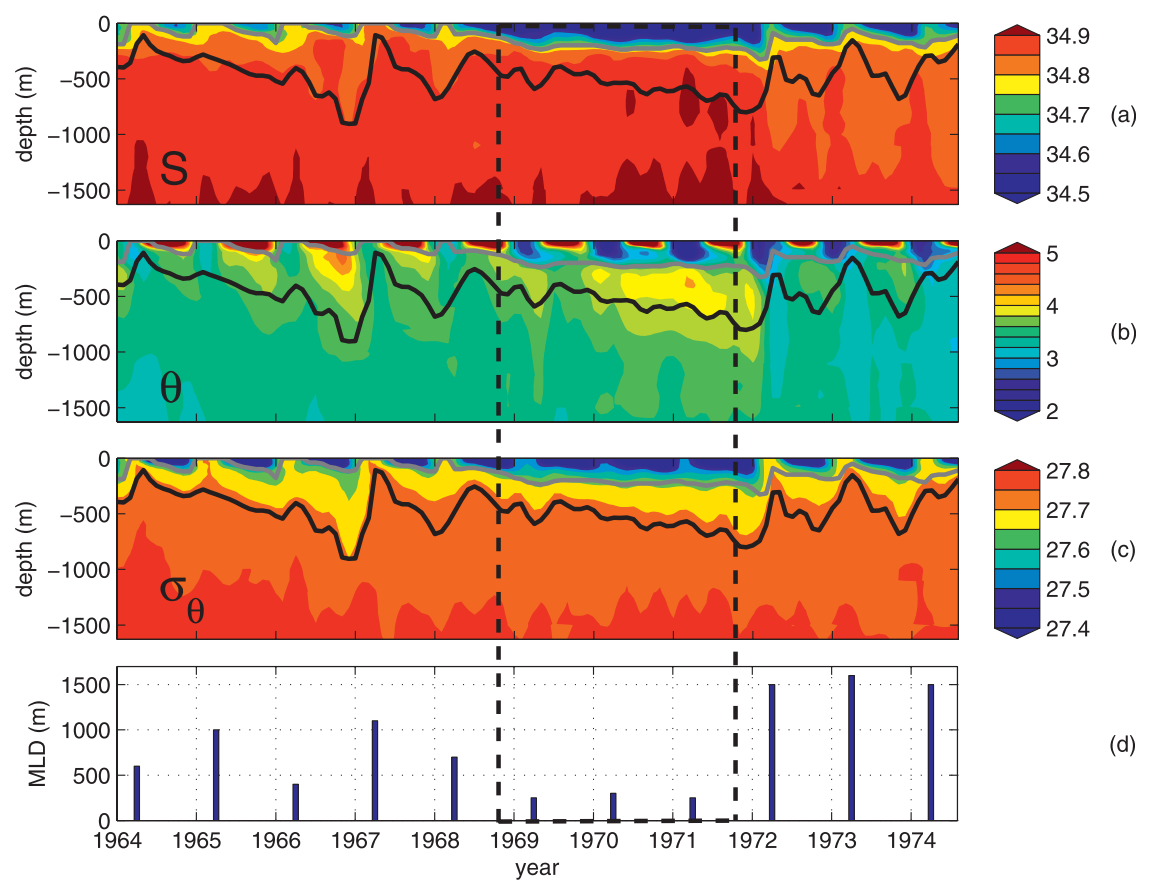

FIG. 1. Time series of the oceanographic measurements taken at Ocean Weather Station Bravo: (a) salinity (psu), (b) potential temperature $\left({ }^{\circ} \mathrm{C}\right),(\mathrm{c})$ potential density $\left(\mathrm{kg} \mathrm{m}^{-3}\right)$, and (d) mixed layer depth (MLD; $\mathrm{m}$ ). The thick gray line is the $S=34.75$ psu isohaline, which we defined as the lower boundary of the cool and fresh upper layer. The thick black line is the $\sigma_{\theta}=$ $27.72 \mathrm{~kg} \mathrm{~m}^{-3}$ isopycnal, which separates the LSW layer from the warm and saline intermediate layer. The dashed box indicates the GSA years.

\section{Air-sea fluxes}

Besides the stratification and water properties described in the previous section, the magnitude of the surface buoyancy flux from the ocean to the atmosphere has a decisive influence on the variability of deep convection. The surface buoyancy flux consists of a surface heat flux and a surface freshwater flux component. Although estimates of the freshwater flux contribution vary because of large uncertainties in the precipitation data (Sathiyamoorthy and Moore 2002; Straneo 2006a), Myers and Donnelly (2008) clearly show this term to be an order of magnitude smaller than the heat flux contribution. Moreover, the freshwater flux contribution is such that it adds buoyancy to the ocean surface and thereby inhibits convective mixing (Sathiyamoorthy and Moore 2002; Straneo 2006a; Myers and Donnelly 2008). Thus, the heat flux is the dominant contributor to the surface buoyancy loss in winter. The magnitude of the heat flux and its efficiency in extracting buoyancy from the ocean, in turn, depend on the sea surface conditions. Therefore, these are briefly discussed below before we look at the heat fluxes.

\section{a. Conditions at the air-sea interface}

The sea surface salinity (SSS) time series (Fig. 2a) shows a clear seasonal cycle with maximum SSS around
March and minimum value around October. This is a result of the convergence of freshwater from remote oceanic sources, precipitation, and vertical mixing into the saline subsurface layer in winter (Kuhlbrodt et al. 2001; Houghton and Visbeck 2002; Schmidt and Send 2007). After the winter of 1968 the SSS strongly decreased because of the GSA. The freshening continued up to early 1972, when winter convective mixing with the salty subsurface layer restored the SSS toward the pre-GSA level.

The SST and surface air temperature (SAT) display a clear seasonal cycle as well ${ }^{3}$ (Fig. 2b). In summer, the SST and SAT are very similar and show little interannual variability. In contrast, wintertime SATs are generally much lower than the SSTs. The 3-hourly SAT values are highly variable and the low-passed SATs vary by as much as $7^{\circ} \mathrm{C}$ between winters. Generally, the winters with the lowest SATs were winters with deep

\footnotetext{
${ }^{3}$ Atmospheric measurements and SST observations were taken at OWS Bravo every $3 \mathrm{~h}$ and thus had a much higher frequency than the deep oceanographic observations. From the Comprehensive Ocean-Atmosphere Data Set (COADS) we retrieved the data from 1964 to 1972. The data from 1973 and 1974 were not available.
} 


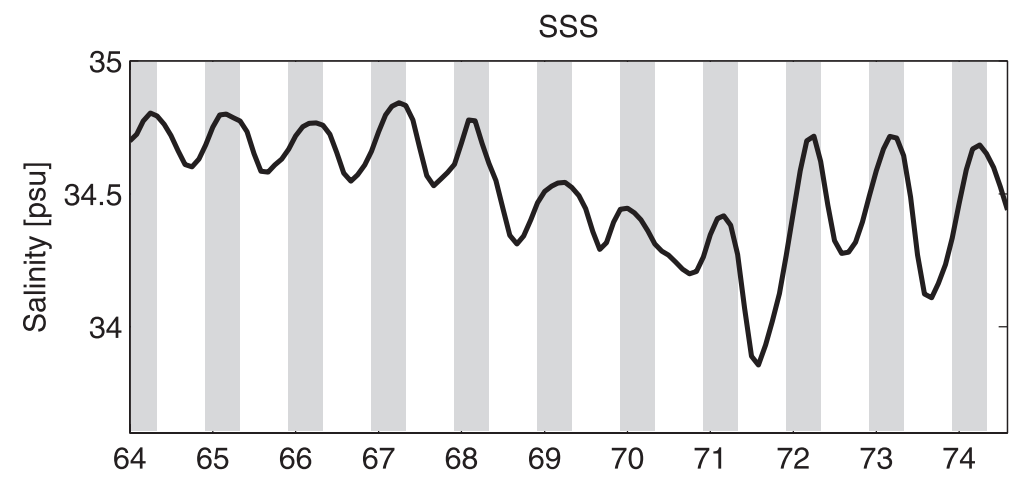

(a)

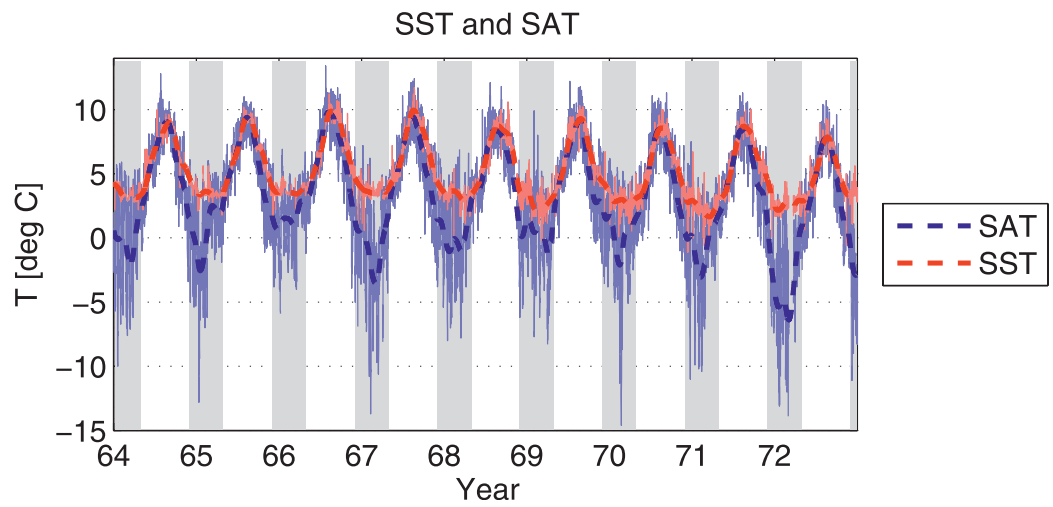

(b)

FIG. 2. Conditions at the air-sea interface measured at OWS Bravo. (a) Monthly mean SSS, and (b) SAT at 2-m height (blue) and SST (red). The thin lines are the 3-hourly values and the thick dashed lines show the 2-month low-passed time series. In both panels the shading marks the convection season (December-April).

convection (e.g., 1967 and 1972), whereas winters with relatively high SATs (e.g., 1966 and 1969) were associated with shallow convective mixing (see also Fig. 1). The wintertime SSTs, on the other hand, are much less variable, with differences on the order of $1^{\circ}$ or $2^{\circ} \mathrm{C}$ between winters. In contrast to the SAT time series, deep convection winters have relatively high SSTs due to convective mixing with the warm subsurface layer, while during winters when convection was very shallow the SSTs declined (Fig. 3). Thus, in the absence of deep convection both the SSS and SST steadily decrease during winter. Convective mixing with the saline and warm subsurface layer levels off this trend for SST and even reverses it in the SSS time series.

\section{b. Heat fluxes}

The surface heat flux is the sum of the sensible heat flux, the latent heat flux, the shortwave incoming radiation, and the net outgoing longwave radiation. During winter the heat flux in the Labrador Sea is dominated by the sensible and latent heat flux components [Fig. 4; note that we use 40-yr European Centre for Medium-Range Weather Forecasts (ECMWF) Re-Analysis (ERA-40) data as, according to Renfrew et al. (2002), these fluxes are within the bounds of observational uncertainty]. As with the SAT time series (Fig. 2b), the deep convection winters are associated with a large heat flux $(1965,1967$, 1968, 1972, 1973, and 1974; note that we will not include 1973 and 1974 in the analysis later on because we do not have the 3-hourly data for these two years). In contrast, the three years without deep convection (1969 to 1971) are associated with a remarkably small heat flux. On average, the mean heat flux over the winter months (December to April) in years with deep convection $\left(193 \mathrm{~W} \mathrm{~m}^{-2}\right)$ is about $70 \%$ larger than in the winters without deep convection $\left(113 \mathrm{~W} \mathrm{~m}^{-2}\right), 56 \%$ of which is due to a change in sensible heat flux, $33 \%$ to latent heat flux, and $11 \%$ to changes in the radiative fluxes.

\section{Absence of deep convection in 1969-71}

In the winters of 1969 to 1971 convective mixing was restricted to the upper $200 \mathrm{~m}$. The absence of deep convection in these winters is generally attributed to anomalously low surface salinity due to the GSA (Dickson et al. 1988; Curry et al. 1998), but the details of the process have 


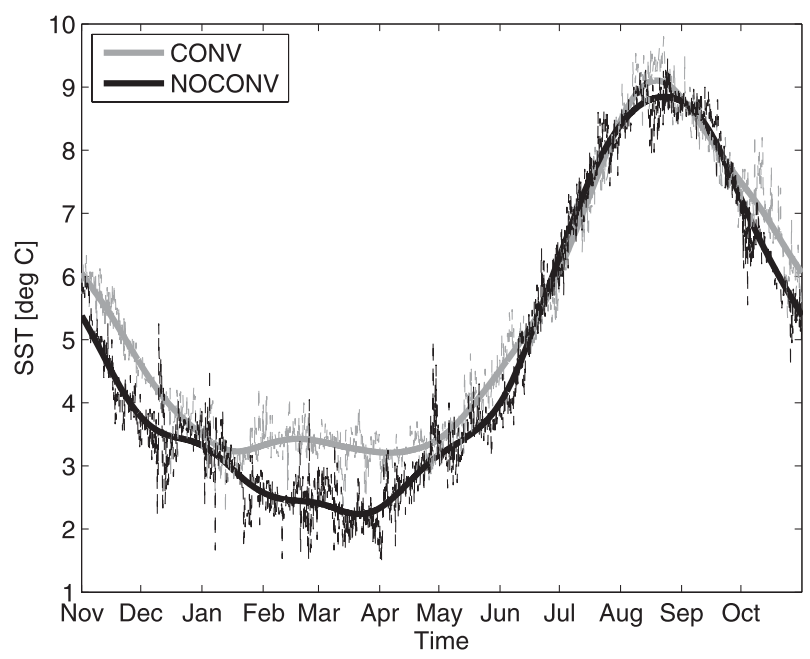

FIG. 3. Mean of the 3-hourly (thin) and a 2-month low-pass filtered (thick) time series of in situ measured SST at the OWS Bravo site (shown in Fig. 2b), for the mean over years without deep convection (NOCONV: 1969, 1970, and 1971; black) and years with deep convection (CONV: 1965, 1967, 1968, and 1972; gray).

never been quantified. A low surface salinity inhibits deep convection in two ways (see the "ocean" box in Fig. 5): 1) by increasing the stratification (Dickson et al. 1988; here discussed in section 4a) and 2) while deep convection is shut down, by decreasing the surface buoyancy flux (section $4 b$ ). The latter effect has been mostly neglected in literature and is shown here to have a nonnegligible impact. It is depicted schematically in Fig. 5 as the "surface feedback loop" and works as follows: when convection is limited to the cold and fresh surface layer, no warm water is mixed upward during the winter months (Fig. 3). Furthermore, the small mixed layer depth implies that the accessible heat reservoir available for cooling is small. Both effects result in a rapid decline of the SST. The low SSTs reduce the heat flux to the atmosphere $Q$ and thus the buoyancy flux. In addition, the thermal expansion coefficient of seawater $\alpha$ is also reduced at lower water temperatures, which further decreases the surface buoyancy flux to the atmosphere. Oceanic conditions aside, the surface buoyancy flux was also limited by the mild winters that occurred during the GSA years (see the "atmosphere" box in Fig. 5). These three contributions to the lower surface buoyancy flux - mild winter, low SST via $Q$, and low SST via $\alpha$-are quantified in section $4 \mathrm{~b}$.

\section{a. Buoyancy storage through increased stratification}

Because of the increasing stratification from 1969 to 1971 (Fig. 1) the "resistance" of the ocean to deep convection increased. To quantify this increase we calculated the amount of buoyancy $(\Delta B)$ that needs to be removed for convection to reach the upper boundary of the LSW layer from early-winter (November) profiles for each year:

$$
\Delta B=\frac{g}{\rho_{0}} \int_{z_{\sigma_{\theta}=27.72}}^{0} \sigma_{\theta} d z,
$$

with $\Delta B$ being the required buoyancy loss to induce deep convection $\left(\mathrm{m}^{2} \mathrm{~s}^{-3} \mathrm{~s}\right), g$ the acceleration due to gravity $\left(9.81 \mathrm{~m} \mathrm{~s}^{-2}\right), \rho_{0}$ a reference density $\left(1027 \mathrm{~kg} \mathrm{~m}^{-3}\right)$, and $\sigma_{\theta}$ the potential density $\left(\mathrm{kg} \mathrm{m}^{-3}\right)\left(z_{\sigma_{\theta}=27.72}\right.$ is the depth of the upper boundary of the LSW layer; Fig. 1). During the period when deep convection was absent (1969 to early 1972), $\Delta B$ initially remained stable, but sharply increased after 1969 (solid line in Fig. 6). Note that the oceanic resistance to convection at the beginning of the winter of 1969 (November 1968) was not unusually high. It is similar in magnitude to the resistance in the winter of 1967 (November 1966), which was a year with deep convection (Fig. 1).

Next, we considered whether changes in $\Delta B$ were due to the buoyancy stored in the cold and fresh upper layer (dotted line in Fig. 6) or the amount stored in the warm and saline intermediate layer (dashed line). The water in both of these layers grew in volume over the summer 1968 to early 1972 period (Fig. 1), but we do not know a priori how much they contributed to the $\Delta B$ increase over this period. Figure 6 clearly shows that the increase in $\Delta B$ during the summer 1968 to early 1972 period is almost entirely due to the increasing buoyancy storage in the upper cold and fresh layer, and that it dominates the increase over the first year. The buoyancy stored in the intermediate warm and saline layer, on the other hand, is more or less constant over the first two years of this period and only shows a steady increase during 1970 and 1971 when the thickness of the layer grew. To summarize, $\Delta B$ increased over the GSA period, although it was not unusually large at the beginning of this period, and this increase is primarily due to the buoyancy stored in the upper fresh layer.

\section{b. Reduced surface buoyancy flux}

In the previous section we estimated how much buoyancy needed to be removed from the ocean to induce deep convection (Fig. 6). Next we consider the magnitude of the buoyancy flux. As mentioned above in section 3, we neglect the freshwater contribution, which is thought to be small. The surface buoyancy flux is then defined (Gill 1982) as

$$
B_{f}=\frac{g \alpha}{\rho_{0} c_{p}}\left[Q_{\mathrm{sens}}+Q_{\mathrm{lat}}+Q_{\mathrm{lw}}-Q_{\mathrm{sw}}\right]
$$



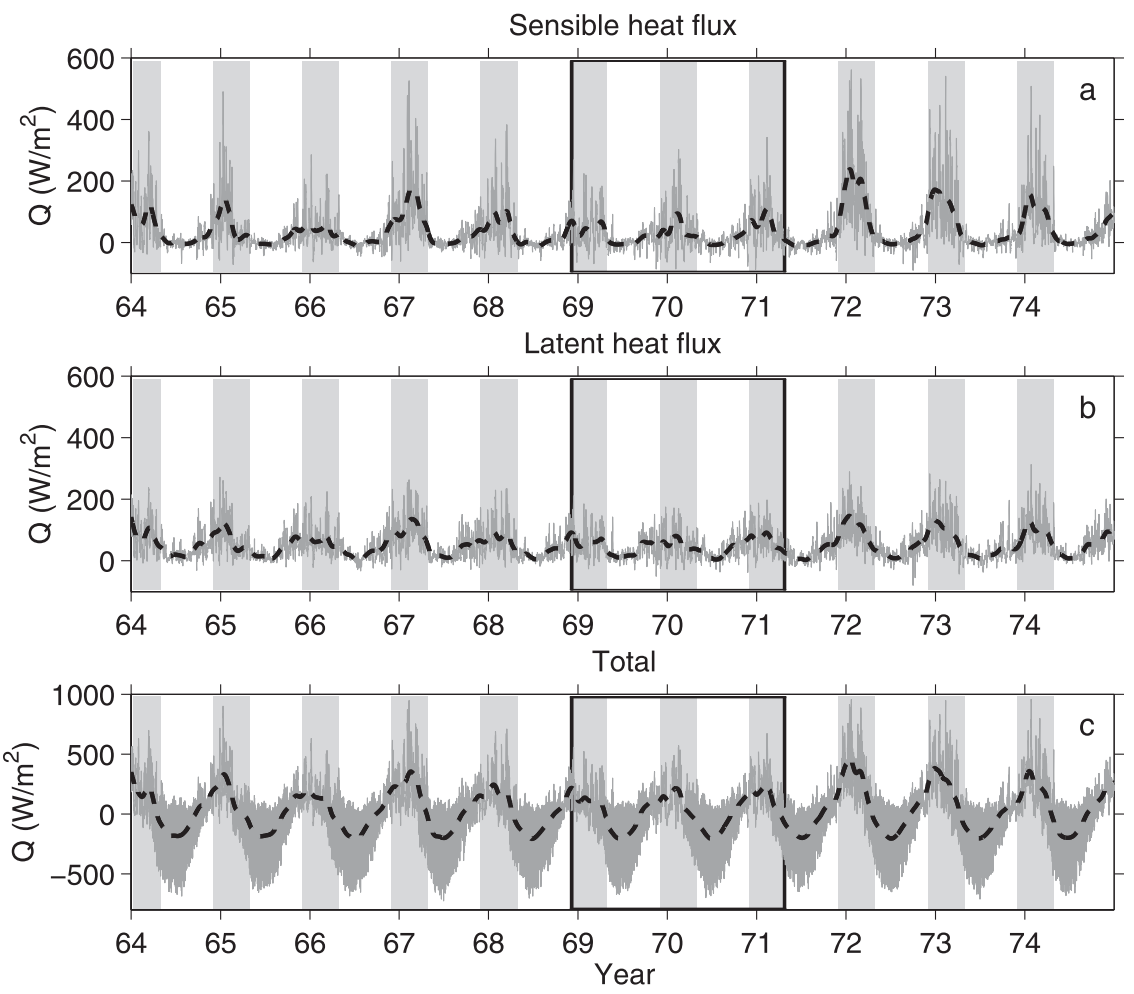

FIG. 4. Heat-flux components over the central Labrador Sea (ERA-40; Uppala et al. 2005): (a) sensible heat flux, (b) latent heat flux, and (c) total heat flux (including radiative terms). The gray lines are the 6-hourly values, while the thick black dashed lines are the 2-month low passed time series. The boxes indicate the GSA years and the shading marks the convection season (December-April).

where $g$ is the acceleration due to gravity $\left(\mathrm{m} \mathrm{s}^{-2}\right), \alpha$ the thermal expansion coefficient of seawater $\left({ }^{\circ} \mathrm{C}^{-1}\right)$, $\rho_{0}$ a reference density for seawater $\left(\mathrm{kg} \mathrm{m}^{-3}\right), c_{p}$ the heat capacity $\left[\mathrm{J}\left(\mathrm{kg}^{\circ} \mathrm{C}\right)^{-1}\right]$, and $Q_{\text {sens }}, Q_{\mathrm{lat}}, Q_{\mathrm{lw}}$, and $Q_{\mathrm{sw}}$ $\left(\mathrm{W} \mathrm{m}^{-2}\right)$ are the sensible and latent heat flux and the heat fluxes due to longwave and shortwave radiation, respectively.

The objective of this section is to assess why the surface buoyancy loss during the 1969 to 1971 winters, when convection did not reach beyond the upper fresh and cold surface layer (hereafter "NOCONV years"), was smaller than during deep convection winters (1965, 1967, 1968, and 1972, hereafter "CONV years"; note that 1964 could in principle be considered a CONV year, but is excluded from the analysis as only part of this winter is covered by the dataset). There are two possible mechanisms (see Fig. 5):

1) Mild winters $\Rightarrow$ small heat flux $Q \Rightarrow$ small buoyancy flux $B_{f}$

2) Cold ocean surface (low SST) $\Rightarrow$ small heat flux $Q$ and low thermal expansion coefficient $\alpha \Rightarrow$ small buoyancy flux $B_{f}$
As the surface buoyancy loss is a function of the coupled ocean-atmosphere conditions it is difficult to separate these mechanisms. If we assume, however, that the air temperature is mostly related to larger-scale atmospheric features (e.g., wind direction) rather than to the SST, we can look at anomalies of just one of these mechanisms at a time. Support for this assumption is found in the fact that when the SAT is high, the SST is low and vice versa, which is not what one would expect if SST had a significant impact on the local SAT.

The sensible and latent heat fluxes were calculated using the Coupled Ocean-Atmosphere Response Experiment (COARE) bulk flux formulas (Fairall et al. 2003). In these formulas the heat fluxes are both a function of the wind speed (including a gustiness factor) and a transfer coefficient, which depends on the stability of the atmosphere. The sensible heat flux furthermore depends on the air-sea temperature difference, while the latent heat flux is a function of the difference between the water vapor mixing ratio in the atmosphere and the interfacial water vapor mixing ratio. The fluxes were first calculated for the observed atmospheric and oceanic conditions to obtain the actual heat flux and 


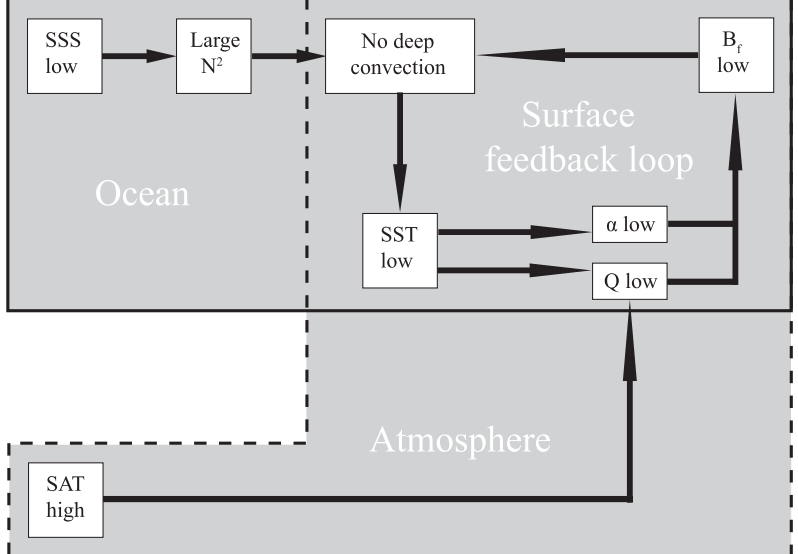

FIG. 5. Schematic showing the feedbacks associated with the shutdown of deep convection in the winters of 1969 to 1971. SSS is sea surface salinity; $N^{2}$ is the Brunt-Väisälä frequency, a measure of ocean stratification; $B_{f}$ is surface buoyancy flux; SST is sea surface temperature; $\alpha$ is the thermal expansion coefficient of seawater (at the surface); $Q$ is the surface heat flux; and SAT is surface air temperature.

buoyancy flux during the CONV and NOCONV winters. It was found that, on average, the winter heat flux in CONV winters was $65 \%$ larger ${ }^{4}$ than in the NOCONV winters, while the mean winter buoyancy flux was $76 \%$ larger (Table 1).

Next, we combine the oceanic conditions of for example the (NOCONV) 1969 winter with the atmospheric conditions of the (CONV) 1965 winter to examine how much larger the heat flux would have been if the 1969 winter had not been so mild. To examine the impact of a cold ocean, on the other hand, we use the atmospheric conditions of the (NOCONV) 1969 winter with the oceanic conditions of the (CONV) 1965 winter. This gives an idea how much larger the heat flux would have been if the ocean surface had been warmer. This procedure is applied to all possible combinations of winters and then results are averaged. Finally, for all those combinations we calculate from Eq. (2) how much larger the buoyancy flux would have been, both through the increased heat flux and, in the case of different oceanic conditions, through the larger $\alpha$. By doing this, we necessarily neglect the radiation terms in Eq. (2), but this does not affect the results significantly as from the ERA-40 reanalysis it is found that the radiation terms together only explain about $10 \%$ of the difference in

\footnotetext{
${ }^{4}$ The difference with the $70 \%$ reported in section $3 \mathrm{~b}$ is mainly because the present number does not include radiation terms. About $1 \%$ is due to the difference between our own calculations from the bulk formulas with Bravo data (this section) and ERA-40 data (section 3b).
}

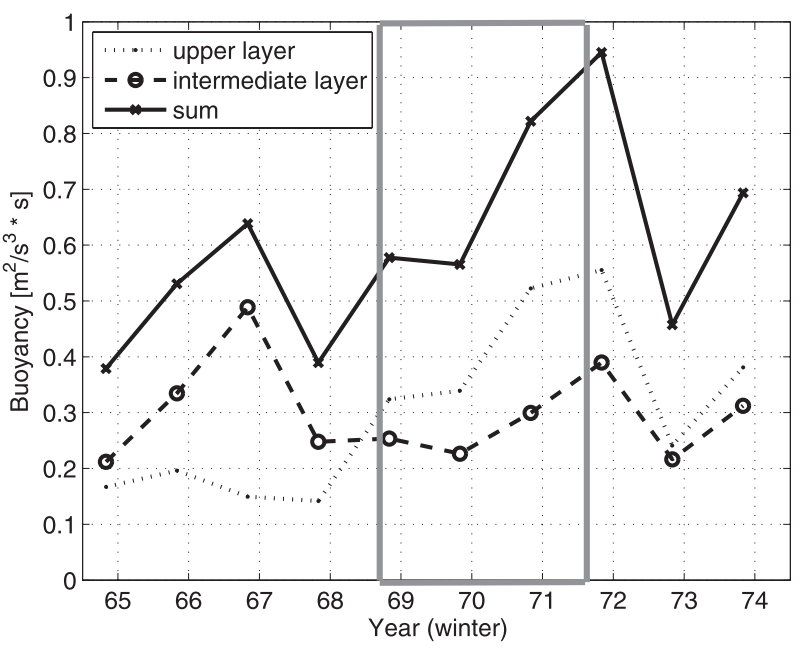

FIG. 6. Oceanic buoyancy loss required for convection to reach the top of the LSW layer (solid line), the bottom of the upper cold and fresh layer (dotted line), and from the top to the bottom of the intermediate warm and saline layer (dashed line) at the onset of each winter (November). The solid line is thus the sum of the dashed and the dotted lines. The layers are defined in the section 2 and Fig. 1. The gray box indicates the GSA years.

the total heat flux between the CONV and the NOCONV winters.

The heat fluxes are calculated with the 3-hourly Bravo data for atmospheric measures and SST. The thermal expansion coefficient $\alpha$ is calculated using the highresolution SST data, and SSS data linearly interpolated to the same 3-hourly resolution. An overview of the cases is given in Table 1 .

\section{1) MiLd WINTER EFFECT ON THE BUOYANCY FLUX}

To quantify the impact of the mild winters we compare the heat and buoyancy fluxes of the NOCONV years with those obtained using atmospheric conditions of the (harsh) CONV winters and oceanic conditions from the (mild) NOCONV winters. We find that the average winter heat and buoyancy flux would have been $42 \%$ larger if the atmospheric conditions alone had been different (Table 1 and dash-dotted line in Fig. 7).

\section{2) COLD OCEAN SURFACE EFFECT ON THE BUOYANCY FLUX}

Second, the effect of the low SST on the buoyancy flux is estimated. This effect has two contributions: from the heat flux and from $\alpha$ (Fig. 5). The heat flux contribution is due to both the sensible and latent heat fluxes. The former depends on the temperature gradient between the ocean and the atmosphere (i.e., a colder ocean can give up less heat). As the wintertime SST was lower by 
TABLE 1. The buoyancy flux increase with respect to the mean buoyancy flux over the NOCONV winters (NC; 1969-71) is calculated for two hypothetical cases (see text). For reference, the top two rows of this table give the mean winter heat $\left(Q ; \mathrm{W} \mathrm{m}^{-2}\right)$ and buoyancy $\left(\mathrm{Bf} ; \mathrm{m}^{2} \mathrm{~s}^{-3}\right.$ ) fluxes over the NOCONV and CONV winters $(\mathrm{C} ; 1965,1967,1968$, and 1972). Here $\Delta Q$ and $\Delta \mathrm{Bf}$ represent the increase of the heat and buoyancy flux respectively with respect to the mean over the NOCONV winters.

\begin{tabular}{llccccc}
\hline & Ocean & Atmosphere & $Q$ & $\mathrm{Bf}\left(\times 10^{-8}\right)$ & $\Delta Q$ & $\Delta \mathrm{Bf}$ \\
\hline NOCONV & $\mathrm{NC}$ & $\mathrm{NC}$ & 105 & 2.19 & & \\
CONV & $\mathrm{C}$ & $\mathrm{C}$ & 173 & 3.86 & $65 \%$ & $76 \%$ \\
Cold winter & $\mathrm{NC}$ & $\mathrm{C}$ & 149 & 3.12 & $42 \%$ & $42 \%$ \\
$\begin{array}{l}\text { Warm ocean } \\
\quad \text { surface }\end{array}$ & $\mathrm{C}$ & $\mathrm{NC}$ & 127 & 2.92 & $21 \%$ & $33 \%$ \\
\hline
\end{tabular}

about $1^{\circ} \mathrm{C}$ (Fig. 3), we expect a reduction of the heat flux. The latent heat flux is also reduced because of lower SSTs, as the saturation value of the air just above the sea surface is lower. Because of the lower SST (and SSS), $\alpha$ is reduced on average over the whole winter by about $10 \%$.

The combined effect of the reduced heat flux and $\alpha$ resulting from the low ocean surface temperature is investigated by combining NOCONV atmospheric conditions with CONV oceanic conditions (Table 1 and dashed line in Fig. 7). The winter heat flux would have been $21 \%$ larger during the NOCONV years if the oceanic conditions had been those of the CONV years, while the buoyancy flux would have been $33 \%$ larger (the impact on the buoyancy flux is larger because $Q$ and $\alpha$ are both larger for a higher SST). The surface buoyancy flux would thus have been $21 \%$ larger because of the $Q$ feedback, while the $\alpha$ feedback gives an additional $12 \%$.

\section{3) CONCLUSIONS ON MILD WINTER AND LOW SST EFFECTS ON THE BUOYANCY FLUX}

In summary, the winter surface buoyancy flux in the years with deep convection was $76 \%$ larger than in the years when convection was restricted to the cold and fresh surface layer. This was partly caused by lower SSTs in the NOCONV years (as a result of lack of convective mixing with the warm intermediate layer) and partly by the mild NOCONV winters. While the contribution of the atmosphere to the surface heat flux increase $(+42 \%)$ is twice that of the ocean $(+21 \%)$, the contribution of the atmosphere to the buoyancy flux is only slightly larger $(+42 \%$ versus $+33 \%)$ because of an additional feedback in the ocean component via the thermal expansion coefficient $\alpha$. In other words, the reduced buoyancy loss during the NOCONV years was in almost equal parts due to mild winters and to having lower SSTs.

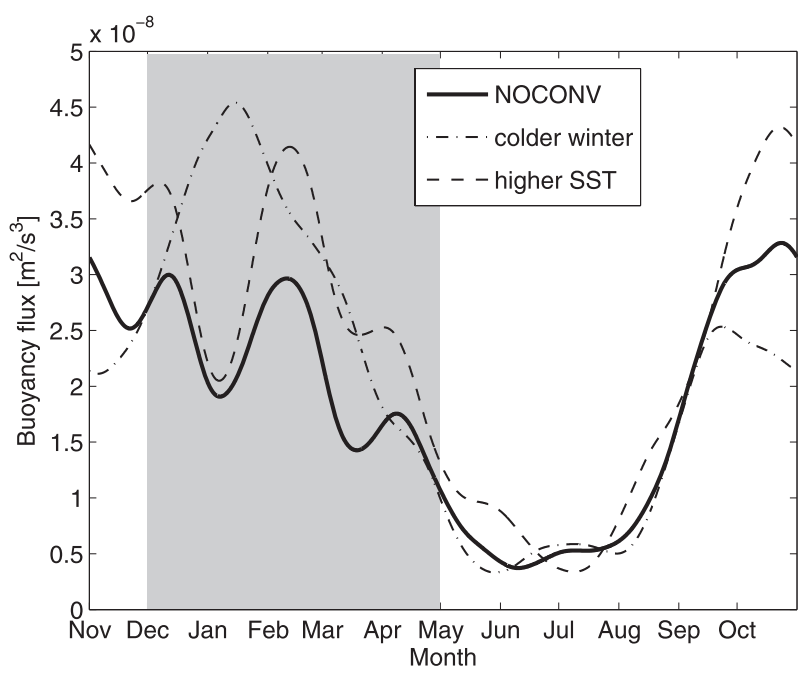

FIG. 7. Results of the surface buoyancy flux calculations for two hypothetical cases (see Table 1). The buoyancy flux in the NOCONV years is given for reference as the solid line. The gray period indicates the convective season (December-April).

\section{c. Cause of the shutdown: 1D mixed layer model analysis}

\section{1) 1D MIXED LAYER MODEL}

For a conclusive answer to the question whether the ocean or the atmosphere was solely responsible for the sudden cessation of convection in the winter of 1969 , or whether it was a combination of the two, we simulated the convection season with a $1 \mathrm{D}$ mixed layer model (Price et al. 1986). This model relies on bulk stability considerations to calculate the mixed layer depth. It calculates the density profile using the nonlinear equation of state, then applies surface heat and freshwater fluxes, and finally deepens the mixed layer until static stability is achieved in the density profile and a bulk Richardson number criterion is satisfied for wind mixing. A gradient Richardson number criterion is used to smooth the sharp gradient below the mixed layer. This relatively simple model has been successfully used before to simulate deep convection in the Labrador Sea (Bramson 1997) as well as the Irminger Sea (Våge et al. 2008). The model is initialized with the observed November profiles for temperature and salinity. [The results are not very sensitive to the choice to use November profiles as other initial conditions (October, December, or January) give similar results; the choice is supported by model results from Mizoguchi et al. (2003), who observed that the preconditioning in November contributes significantly to the determination of the convection depth.]

The model is forced by surface heat fluxes and lateral freshwater fluxes. For the heat fluxes the 6-hourly ERA-40 
(Uppala et al. 2005) surface fluxes are used (Fig. 4). This choice is based on a comparison of the sensible and latent heat fluxes from ERA-40 and the recalibrated National Centers for Environmental Prediction (NCEP) dataset (Kistler et al. 2001; Renfrew et al. 2002) with our own calculation of the fluxes from observations at OWS Bravo using the COARE bulk formulas. The ERA-40 fluxes closely resembled our own estimates. Note that we need a reanalysis product for an estimate of the incoming shortwave radiation and net outgoing longwave radiation, which we cannot calculate with bulk formulas. Lateral heat fluxes are ignored because, in the presence of strong surface fluxes and deep convection, it is not feasible to extract the necessary information on lateral heat fluxes from the OWS Bravo data. This does not pose a problem, however, because they are relatively small compared to the surface heat flux in winter (Straneo 2006a) and the mixed layer temperature be can fairly well simulated by the 1D model without lateral heat fluxes (which supports the previous statement that the surface fluxes dominate).

In the case of freshwater fluxes the situation is reversed. While the exact magnitude of the surface freshwater flux is uncertain, the literature suggests a minor role of the surface fluxes with respect to lateral fluxes (Lazier 1980; Khatiwala et al. 2002; Straneo 2006a). Although in some years the lateral salinity flux is small, in other years it must be included in the model calculations to obtain a realistic mixed layer depth and properties. Therefore, the surface freshwater flux is ignored and the lateral salinity fluxes are simulated by restoring the salinity over the whole depth of the profile to the monthly mean observed profiles (Fig. 1) with a restoring time scale of a month.

\section{2) Model Results}

The first hypothesis that is tested using the 1D mixed layer model is whether convection ceased only because of the low SSS and SST (as a result of the GSA; see the ocean box in Fig. 5). If this were the case, no reasonable winter heat flux could have induced deep convection in these winters. To test this we initialized the mixed layer model with the observed November profiles of temperature and salinity from the winters of 1969, 1970, and 1971. Then the model was forced with increasingly larger heat fluxes, until the minimum heat flux was found that resulted in deep convective mixing (mixing down to the LSW layer).

In Fig. 8 the winter (December to April) surface heat fluxes from the ERA-40 reanalysis are given for the winters of 1960 to 1999 . The NOCONV winters are indicated by open squares and the winter of 1972, when deep convection returned, is highlighted by the filled circle. To put these values in perspective, consider that

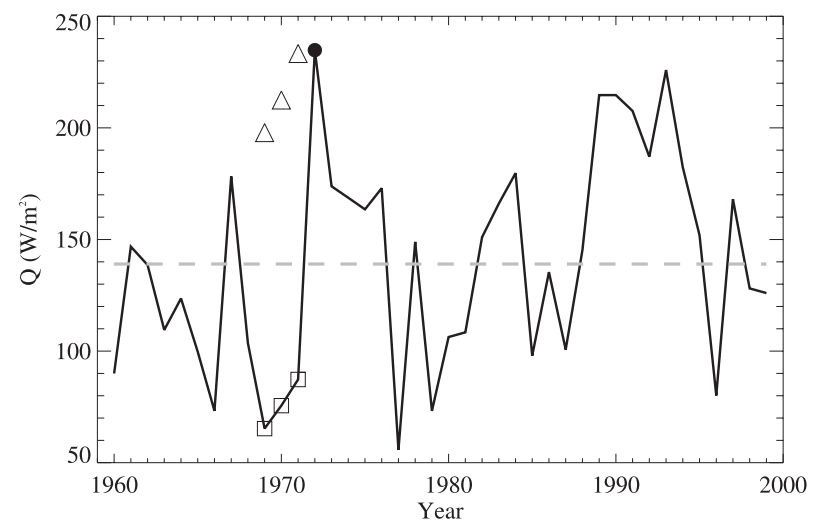

FIG. 8. Mean winter (December-April) surface heat loss from the ERA-40 reanalysis. The gray dashed line is the mean value over the 40 -yr time series $\left(139 \mathrm{~W} \mathrm{~m}^{-2}\right)$. The open squares are the NOCONV years (1969-71) and the closed circle is the winter of 1972 when deep convection returned. The open triangles indicate the heat flux required for deep convection to occur in the NOCONV winters.

the winter heat loss in 1972 was $69 \%$ larger than the 40 -year mean of $139 \mathrm{~W} \mathrm{~m}^{-2}$, while the winter heat loss in 1969 to 1971 was up to $53 \%$ smaller. The heat flux required to induce deep convection in the model simulations is indicated by the open triangles in Fig. 8. The likelihood of obtaining these heat fluxes (or larger ones) in the 40 years of the ERA- 40 record is $12.5 \%, 10 \%$, and $2.5 \%$ for 1969,1970 , and 1971 , respectively. A harsher winter in 1969 would thus have induced deep convection despite the cold and fresh surface layer in the ocean, even though the likelihood of deep convection decreased rapidly afterward through the continuing freshening of the surface layer and the surface feedbacks explained in section $4 \mathrm{~b}$.

The second hypothesis that we can test is whether convection ceased only because of the mild winters (see the atmosphere box in Fig. 5). If this were the case, the 1969 winter heat flux would not have caused deep convection in other winters with "normal" oceanic conditions either. We therefore used the model to predict the extent of convection using the November temperature and salinity profiles of non-GSA winters and the 1969 winter heat flux. In the winter of 1965, when the LSW layer was closer to the surface, this heat flux would have been sufficient to induce deep convective mixing. For 1968 the mixing depth is on the edge of the LSW layer, and in all the other years no deep convection would have taken place. The likelihood of deep convection with the 1969 winter heat flux is thus at least 1 (possibly 2) out of 10 winters. In conclusion, although the sea surface conditions were unusual and the winters were unusually mild, it was the combination of these two effects that was responsible for the complete shutdown of deep convection during the GSA winters. 


\section{Return of deep convection in $\mathbf{1 9 7 2}$}

In the winter of 1972 deep convection returned (Fig. 1). Here we examine whether this was due to the very harsh winter of 1972 or to changes in the oceanic conditions. We know from Fig. 6 that the amount of buoyancy needed to be removed for deep convection in 1972 was the highest in this decade-long record. Also, Fig. 2a shows that the surface salinity in the beginning of the winter of 1972 was still very low. The oceanic conditions at the start of the convection season were thus not favorable at all for deep convection. That being said, they may have changed over the course of the winter because of lateral fluxes, for example because the GSA was moving away at the time (Dickson et al. 1988). On the other hand, the winter heat flux was exceptionally large as this was a very harsh winter (Figs. 2b, 4, and 8). The atmospheric conditions were thus very favorable for deep convection.

To answer the question of whether the ocean or the atmosphere was responsible for the return of deep convection we again used the $1 \mathrm{D}$ mixed layer model. To study the effect of the large heat flux alone, we first calculated the evolution of the mixed layer over the winter of 1972 without (lateral) salinity fluxes, the surface heat flux thus being the only forcing. Our model run shows that convection would not have reached the observed mixed layer depth of $1500 \mathrm{~m}$, but instead only to less than $600 \mathrm{~m}$. The heat flux which would have been required for deep convective mixing is never observed in the 40-yr ERA-40 time series. Also, when a sufficiently large heat flux was imposed to mix down to the observed mixed layer depth, the water in the mixed layer was about $0.2^{\circ} \mathrm{C}$ too cold. This implies that (changes in) the salinity of the water column must have played a role in the resumption of deep convection. When the observed lateral salinity fluxes are added to the model simulations, the mixed layer depth and properties are well captured.

Thus, contrary to what is commonly assumed (Straneo 2006a; Yashayaev 2007), for the deep convection event in the winter of 1972 both the large winter heat flux and a change of oceanic salinity conditions were essential. The salinity change could have been caused either by the withdrawal of the GSA or by a larger than usual lateral eddy flux with a subsurface salinity maximum (Lilly et al. 2003; Hatun et al. 2007). The time resolution of the available oceanographic data is, however, insufficient to be conclusive as to which mechanism was responsible for the change in salinity, because once the water is mixed one does not know whether it originates from the surface or deeper down. A regional model study could provide more insight on this point.

\section{Summary and discussion}

Our analysis shows that the two primary factors that inhibited deep convection during the Great Salinity Anomaly (GSA) period were the mild atmospheric winter conditions of 1969-71 and freshening due to the GSA. The mild winters were associated with a small heat and buoyancy loss to the atmosphere. The way in which the GSA affected convection is more complex (Fig. 5). The initial response of the Labrador Sea to the GSA was an increasing stratification, which inhibited convective mixing into the underlying warm, salty layer. Because of a continuing lateral influx of fresh boundary current water in the upper layer and saline water in the subsurface layer, the stratification continued to increase (Fig. 6), which made a resumption of deep convection increasingly more difficult [a phenomenon previously described by Welander (1982), Lenderink and Haarsma (1994), and Kuhlbrodt et al. (2001)]. Furthermore, two positive feedbacks ensued that further decreased the surface buoyancy flux and resulted in the shutdown of convection until the winter of 1972.

The surface feedbacks are as follows (Fig. 5). In a regular convection winter, warm subsurface water is mixed upward and counteracts the surface cooling. When no convection occurs, however, the surface continues to cool down from about $3.2^{\circ} \mathrm{C}$ to about $2.2^{\circ} \mathrm{C}$ (Fig. 3). A lower sea surface temperature (SST) limits the surface sensible and latent heat fluxes to the atmosphere and thus the magnitude of the surface buoyancy flux. The surface buoyancy flux is further diminished by the dependence of the thermal expansion coefficient $\alpha$ on SST [Eq. (2); the mean winter surface $\alpha$ value during the convective winters was $9.4 \times 10^{-5}{ }^{\circ} \mathrm{C}^{-1}$, while in the shutdown winters it was $\left.8.6 \times 10^{-5}{ }^{\circ} \mathrm{C}^{-1}\right]$. Thus, when convection was initially inhibited the ocean surface cooled, which restricted the surface buoyancy fluxes, which in turn inhibited deep convection. There is thus a positive feedback loop that reinforces a shutdown state.

We note that there exists a negative feedback associated with the surface cooling: as the sea surface cools, density increases thus contributing to decreasing the stratification. An estimate of the impact of this negative feedback based on the data shown in Fig. 3 shows, however, that this effect is smaller than the two positive feedbacks mentioned above (not shown).

In this study we quantified the effects of the mild winters and the low surface salinity in the Labrador Sea during the GSA years. First the initial response of the ocean to the low surface salinity, the increasing stratification, was studied (left-hand side of the ocean box in Fig. 5). It was shown that the stratification of the whole 
water column above the LSW layer was not unusually large at the beginning of the winter of 1969, but instead comparable to that of winters when deep convection did take place. A notable difference with deep-convection winters, however, was found in the amount of buoyancy stored in the upper cold and fresh layer, which was the signature of the GSA. The stratification of this upper layer was about twice the pre-GSA value.

Second, the limiting effect of the low SST and the mild winters on the surface buoyancy flux was studied (see the atmosphere box and surface feedback loop in Fig. 5). Using bulk formulas it was shown that the buoyancy flux was $76 \%$ larger in the years with convection with respect to no-convection years. The effect of a harsher winter (the mean 2-m temperature in the convective winters was $-0.7^{\circ} \mathrm{C}$, whereas in the nonconvective winters is was $\left.0.1^{\circ} \mathrm{C}\right)$ on the heat flux $\left(193 \mathrm{~W} \mathrm{~m}^{-2}\right.$ in convective winters versus $113 \mathrm{~W} \mathrm{~m}^{-2}$ in nonconvective winters; Uppala et al. 2005) is much larger than the effect of a higher SST ( $42 \%$ vs $21 \%$ ). We found that this difference was much smaller for the buoyancy flux ( $42 \%$ vs $33 \%$ ), however, because of the additional $\alpha$ feedback.

Using a 1D mixed layer model it was shown that neither the low surface salinity nor the mild winters alone could have prevented deep convection. In the winter of 1969 the magnitude of the winter heat flux needed for deep convection occurred in only $12 \%$ of the years in the ERA-40 40-yr reanalysis dataset. On the other hand, the magnitude of the 1969 winter heat flux would have induced deep convection in years such as 1965 and 1968, two out of the 10-winter Bravo record. So, although in 1969 both the oceanic and atmospheric conditions made deep convection unlikely, it was the combination of the two that set off its shutdown.

The return of deep convection in the winter of 1972 is generally attributed to the very harsh winter and large surface heat flux. The 1D model simulations showed, however, that this heat flux alone, without lateral salinity fluxes, would have been insufficient for deep convection to occur. When the lateral salinity fluxes were added to the simulation, the mixed layer depth and properties were reproduced well by the model. The source of the high salinity water cannot be identified from the data. It could have been the retreat of the GSA, and thus less fresh surface water, or eddy-induced lateral fluxes with a typical subsurface salinity maximum, or both.

So far, we have not specifically discussed the impact of wind forcing. Wind influences deep convection in two ways. The direct mixing effect is small; wind hardly mixes below a depth of several hundred meters, but it is included in the buoyancy flux calculation in section $4 \mathrm{~b}$ and the model simulation in section $4 \mathrm{c}$. The second effect of wind forcing, the wind stress curl effect on the doming of the isopycnals, is left out as the hydrographic data showed no sign of increased doming during the GSA period.

This study has a number of implications for our understanding of the effects of freshwater anomalies on deep convection. First, although changes in both the fresh surface layer and the warm and salty subsurface layer can alter the likelihood of convection, during the GSA years it was primarily the freshening of the upper layer that caused the shutdown. Once deep convection had stopped, both layers contributed to a consolidation of the status quo. In the light of the recent changes in the boundary current characteristics (a warmer and more saline Irminger Current and more freshwater export from the Arctic) this is an important result. It means that, very likely, increasing ice melt in the Arctic is a larger threat to decreasing convection rates than warmer and more saline Irminger Current water. Also, convection resumed because of a lateral salt influx (combined with a very harsh winter). This suggests that since anomalies like the GSA pass, the ocean may naturally recover. Conversely, if the freshwater inflow remains high, deep convection will not resume. Second, it is unclear whether the unusually large heat fluxes in 1972 were a coincidence, or whether the ocean played an active role in this. For example, Våge et al. (2009) suggested that the large sea ice extent in the winter of $2008 \mathrm{kept}$ the passing winds cold, so that the air was still very cold when it reached the central Labrador Sea. Given the anomalous amount of freshwater in the surface layer and the harsh winter in 1972, a similar mechanism could have been at play then. Third, the system is apparently very sensitive to the ocean surface temperature. Once the SST is low, it will tend to remain low because of the surface feedbacks to the buoyancy flux. It is thus of vital importance in ocean and climate models to accurately simulate the ocean surface temperature and its effect on the surface fluxes, and to be particularly careful with restoring SSTs in deep convection areas toward too low or too high temperatures.

Acknowledgments. This research was funded by a grant from the NWO/SRON User Support Programme Space Research. FS acknowledges support from OCE0850416 and NOAA NA08OAR4310569.

\section{REFERENCES}

Alley, R. B., and Coauthors, 2003: Abrupt climate change. Science, 299, 2005-2010.

Belkin, I. M., S. Levitus, J. Antonov, and S.-A. Malmberg, 1998: "Great salinity anomalies" in the North Atlantic. Prog. Oceanogr., 41, 1-68.

Biastoch, A., C. W. Böning, and J. Getzlaff, 2008: Causes of interannual-decadal variability in the meridional overturning circulation of the midlatitude North Atlantic Ocean. J. Climate, 21, 6599-6615. 
Bramson, L., 1997: Air-sea interactions and deep convection in the Labrador Sea. M.S. thesis, Dept. of Oceanography, Naval Postgraduate School, 76 pp.

Broecker, W. S., 1997: Thermohaline circulation, the Achilles heel of our climate system: Will man-made $\mathrm{CO}_{2}$ upset the current balance? Science, 278, 1582-1588.

- D. M. Peteet, and D. Rind, 1985: Does the ocean-atmosphere system have more than one stable mode of operation? Nature, $\mathbf{3 1 5}, 21-26$.

Clark, P. U., N. G. Pisias, T. F. Stocker, and A. J. Weaver, 2002: The role of the thermohaline circulation in abrupt climate change. Nature, 415, 863-869.

Curry, R. G., M. S. McCartney, and T. M. Joyce, 1998: Oceanic transport of subpolar signals to mid-depth subtropical waters. Nature, 391, 575-577.

Dickson, R. R., J. Meincke, S. Malmberg, and A. J. Lee, 1988: The "Great Salinity Anomaly" in the northern North Atlantic 1968-1982. Prog. Oceanogr., 20, 103-151.

Eden, C., and J. Willebrand, 2001: Mechanism of interannual to decadal variability of the North Atlantic circulation. J. Climate, 14, 2266-2280.

Fairall, C. W., E. F. Bradley, J. E. Hare, A. A. Grachev, and J. B. Edson, 2003: Bulk parameterization of air-sea fluxes: Updates and verification for the COARE algorithm. J. Climate, 16, 571-591.

Ganachaud, A., and C. Wunsch, 2000: Improved estimates of global ocean circulation, heat transport and mixing from hydrographic data. Nature, 408, 453-457.

Gill, A. E., 1982: Atmosphere-Ocean Dynamics. Academic Press, $662 \mathrm{pp}$.

Haak, H., J. Jungclaus, U. Mikolajewicz, and M. Latif, 2003: Formation and propagation of great salinity anomalies. Geophys. Res. Lett., 30, 1473, doi:10.1029/2003GL017065.

Häkkinen, S., 1999: A simulation of thermohaline effects of a great salinity anomaly. J. Climate, 12, 1781-1795.

Hatun, H., C. C. Eriksen, and P. B. Rhines, 2007: Buoyant eddies entering the Labrador Sea observed with gliders and altimetry. J. Phys. Oceanogr., 37, 2838-2854.

Houghton, R. W., and M. H. Visbeck, 2002: Quasi-decadal salinity fluctuations in the Labrador Sea. J. Phys. Oceanogr., 32, 687701.

IOC, SCOR, and IAPSO, 2010: The international thermodynamic equation of seawater 2010: Calculation and use of thermodynamic properties. Intergovernmental Oceanographic Commission, Manuals and Guides No. 56, UNESCO, 196 pp. [Available online at http://unesdoc.unesco.org/images/0018/ 001881/188170e.pdf.]

Khatiwala, S., P. Schlosser, and M. Visbeck, 2002: Rates and mechanisms of water mass transformation in the Labrador Sea as inferred from tracer observations. J. Phys. Oceanogr., 32, 666-686.

Kistler, T., and Coauthors, 2001: The NCEP-NCAR 50-Year Reanalysis: Monthly means CD-ROM and documentation. Bull. Amer. Meteor. Soc., 82, 247-267.

Kuhlbrodt, T., S. Titz, U. Feudel, and S. Rahmstorf, 2001: A simple model of seasonal open ocean convection. Part II: Labrador Sea stability and stochastic forcing. Ocean Dyn., 52, 36-49.

—, A. Griesel, M. Montoya, A. Levermann, M. Hofmann, and S. Rahmstorf, 2007: On the driving processes of the Atlantic meridional overturning circulation. Rev. Geophys., 45, RG2001, doi:10.1029/2004RG000166.

Kwok, R., G. F. Cunningham, M. Wensnahan, I. Rigor, H. J. Zwally, and D. Yi, 2009: Thinning and volume loss of the
Arctic Ocean sea ice cover: 2003-2008. J. Geophys. Res., 114, C07005, doi:10.1029/2009JC005312.

Lazier, J. R. N., 1980: Oceanographic conditions at ocean weather ship Bravo, 1964-1974. Atmos.-Ocean, 18, 227-238.

Lenderink, G., and R. J. Haarsma, 1994: Variability and multiple equilibria of the thermohaline circulation associated with deep-water formation. J. Phys. Oceanogr., 24, 1480-1493.

Lilly, J. M., P. B. Rhines, F. Schott, K. Lavender, J. Lazier, U. Send, and E. D'Asaro, 2003: Observations of the Labrador Sea eddy field. Prog. Oceanogr., 59, 75-176.

Marotzke, J., and J. R. Scott, 1999: Convective mixing and the thermohaline circulation. J. Phys. Oceanogr., 29, 2962-2970.

Marshall, J., and R. Schott, 1999: Open ocean deep convection: Observations, models and theory. Rev. Geophys., 37, 1-64.

Maslanik, J., J. Stroeve, C. Fowler, and W. Emery, 2011: Distribution and trends in Arctic sea ice through spring 2011. Geophys. Res. Lett., 38, L13502, doi:10.1029/2011GL047735.

McDougall, T. J., D. R. Jackett, and F. J. Millero, 2009: An algorithm for estimating absolute salinity in the global ocean. Ocean Sci. Discuss., 6, 215-242, doi:10.5194/osd-6-215-2009.

Mizoguchi, K., S. L. Morey, J. Zavala-Hidalgo, N. Suginohara, S. Häkkinen, and J. J. O'Brien, 2003: Convective activity in the Labrador Sea: Preconditioning associated with decadal variability in subsurface ocean stratification. J. Geophys. Res., 108, 3330, doi:10.1029/2002JC001735.

Myers, P. G., and C. Donnelly, 2008: Water mass transformation and formation in the Labrador Sea. J. Climate, 21, 1622-1638.

Price, J. F., R. A. Weller, and R. Pinkel, 1986: Diurnal cycling: Observations and models of the upper ocean response to diurnal heating, cooling, and wind mixing. J. Geophys. Res., 91 (C7), 8411-8427.

Renfrew, I. A., G. W. K. Moore, P. S. Guest, and K. Bumke, 2002: A comparison of surface layer and surface turbulent flux observations over the Labrador Sea with ECMWF analyses and NCEP reanalyses. J. Phys. Oceanogr., 32, 383-400.

Rignot, E., I. Velicogna, M. R. van den Broeke, A. Monaghan, and J. T. M. Lenaerts, 2011: Acceleration of the contribution of the Greenland and Antarctic ice sheets to sea level rise. Geophys. Res. Lett., 38, L05503, doi:10.1029/2011GL046583.

Sathiyamoorthy, S., and G. W. K. Moore, 2002: Buoyancy flux at ocean weather station Bravo. J. Phys. Oceanogr., 32, 458-474.

Schmidt, S., and U. Send, 2007: Origin and composition of seasonal Labrador Sea freshwater. J. Phys. Oceanogr., 37, 1445-1454.

Stommel, H. M., 1961: Thermohaline convection with two stable regimes of flow. Tellus, 13, 224-230.

Straneo, F., 2006a: Heat and freshwater transport through the central Labrador Sea. J. Phys. Oceanogr., 36, 606-628.

, 2006b: On the connection between dense water formation, overturning, and poleward heat transport in a convective basin. J. Phys. Oceanogr., 36, 1822-1840.

Uppala, S. M., and Coauthors, 2005: The ERA-40 Re-Analysis. Quart. J. Roy. Meteor. Soc., 131, 2961-3012.

Våge, K., R. S. Pickart, G. W. K. Moore, and M. H. Ribergaard, 2008: Winter mixed layer development in the central Irminger Sea: The effect of strong intermittent wind events. J. Phys. Oceanogr., 38, 541-565.

— the subpolar North Atlantic Ocean in winter 2007-2008. Nat. Geosci., 2, 67-72.

Welander, P., 1982: A simple heat-salt oscillator. Dyn. Atmos. Oceans, 6, 233-242.

Yashayaev, I., 2007: Hydrographic changes in the Labrador Sea, 1960-2005. Prog. Oceanogr., 73, 242-276. 